\title{
US panel split on endocrine disruptors ...
}

[WASHINGTON] The US Environmental Protection Agency (EPA) is pressing ahead with a plan to screen 15,000 chemicals for their possible effects as endocrine disruptors in animals and humans - without recourse to what some claim to be adequate independent scientific advice.

The situation has arisen because of delays, reportedly due to disagreements between experts with conflicting views, in the publication of a long-awaited report from the National Research Council (NRC). According to NRC officials, the report, which is intended to provide a definitive US government, is not now likely to appear until early next year.

An EPA spokeswoman says the environmental agency used its own scientific assessment as the basis for its actions, which could cost hundreds of millions of dollars.

But scientists and officials on both sides of the issue view the non-appearance of the NRC study with alarm. "My feeling is you need to assess the science before you proceed with the screening," says one official.

The NRC, the operating arm of the National Academies of Sciences and Engineering, was set up to provide definitive advice to the government on difficult technical questions. Few problems are tougher or more contentious than the proposed regulation of endocrine disruptors. These are chemicals that, according to the endocrinedisruptor hypothesis favoured by some scientists, can induce a variety of health effects in humans and wildlife by mimicking or interfering with the actions of hormones.

Chemicals identified as endocrine disruptors include some pesticides, industrial chemicals, drugs and contaminants. But industry groups and other scientists say there is no hard evidence linking any of assessment of endocrine disruptors for the

these to human health problems.

The EPA and other government agencies are paying $\$ 860,000$ for the NRC study, which was commissioned in March 1995. The panel first met in October 1995, and was expected to complete its work by the spring of 1997. But that deadline soon slipped to spring of this year, and then to this autumn.

Most of those following the issue now expect publication in December. But Jim Reisa, director of the board on environmental studies and toxicology at the NRC, which is overseeing the study, says he is "not wildly optimistic" that it will appear before 1999.

The NRC panel has been dogged from the beginning by bitter disagreements about the endocrine-disruptor hypothesis. Members of the panel include noted opponents of the

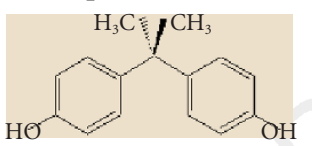

Bisphenol A: one of the suspect chemicals. hypothesis, such as Stephen Safe of Texas A\&M University and James Lamb of Jellinek, Schwartz \& Connelly, an industry consultancy based in Washington, as well researchers who believe their work has verified it, such as Frederick vom Saal of the University of Missouri at Columbia.

The delay has been "mostly due to the difficulty in reaching a consensus among the panel members", says Reisa. "We didn't go into this blindly. We appointed members with strong views on both sides, in the hope that, if we reached a consensus, it would carry great weight. I still hope that we will reach consensus."

According to Reisa, the current version of the report has just come back from 17 external reviewers, who have provided 120 pages of comments for the panel to argue about.

Panel members will not comment on the substance of their disputes. But sources close

\section{while Japan studies drop in sperm counts}

[TOKYO] Japan's Ministry of Health and Welfare announced last week that it is to sponsor a nationwide study of sperm counts. The move follows public concern over the possible effects of endocrine disruptors - manmade chemicals suspected of disrupting human reproductive functions - on male fertility (see above).

Researchers from St Marianna University School of Medicine, Sapporo Medical College, Kanazawa University and Osaka
University plan to begin the project later this year. According to the health ministry, semen samples will be collected from 1,500 men from all over Japan. The samples will be tested to determine the number of sperm per millilitre and the percentage of sperm with normal motility. The researchers also hope to determine whether certain types of food have any effect on sperm levels.

Widespread concern about the effects of endocrine disruptors was triggered last year by the release of a report by the Environment Agency, which listed 67 chemical compounds, such as dioxins and polychlorinated biphenyl compounds (PCBs), that are suspected of mimicking natural sex hormones.

The government has since allocated $¥ 18$ billion (US\$152 million) for research into the effects of such compounds on human health (see Nature 392, 748; 1998). to some of them say the main draft is cautious in its assessment of the extent to which endocrine disruptors pose a risk to human health.

Four environmentally inclined members of the panel, including vom Saal and Ana Soto of Tufts University, are said to be holding out against the draft. They have submitted their own alternative executive summary of the report, which may end up as a minority appendix attached to the main study. The NRC tries to avoid issuing minority reports, but occasionally does so.

The conflict has left supporters of the endocrine-disruptor hypothesis playing down expectations of the study, which was supposed to provide the scientific basis for US government policy. Pete Myers, for example, director of the W. Alton Jones Foundation in Charlottesville, Virginia, suggests that the impact of the report "will depend on whether it is able to rise above the politics" of the issue.

"The report has suffered because of the willingness of some people on the panel to engage in political debate" during the course of the study, argues Myers. He accuses Safe and Lamb, in particular, of such activity.

Two weeks ago Lamb took part in a press conference in Washington at the Society of the Plastics Industry to release an unpublished study, sponsored by the plastics industry. The study refutes a recent finding by vom Saal that bisphenol A, a chemical used in plastics production, caused prostrate growth and low sperm counts in mice ( Toxicology and Industrial Health 14, 239; 1998).

Lamb said he had reviewed the unpublished study, and found its methodology superior to vom Saal's.

Perhaps the only aspect on which the two sides of the argument agree is that the delays in the NRC study will diminish its impact. The EPA, responding to laws passed in 1996, established its own Endocrine Disruptor Screening and Testing Advisory Committee, which last month recommended that 15,000 chemicals should be screened and, if necessary, tested on animals for health effects.

Earlier this month, the EPA accepted its recommendations and said it would prepare a screening process by March of next year. According to scientists on both sides of the argument, the NRC report was originally supposed to provide the scientific basis for this process.

But the train of endocrine-disruptor regulation is now leaving the station, raising doubts about the usefulness of the NRC's meticulous study process in the context of fast-moving policy debates. Reisa can suggest only one way in which it could have been speeded up: "We could have picked an easier subject!"

Colin Macilwain 